\title{
The Main Anatomic Variations of the Hepatic Artery and Their Importance in Surgical Practice: Review of the Literature
}

\author{
George Noussios ${ }^{\mathrm{a}}$, Ioannis Dimitriou ${ }^{\mathrm{a}}$, Iosif Chatzis ${ }^{\mathrm{b}}$, \\ Anastasios Katsourakis ${ }^{b, c}$
}

\begin{abstract}
Anatomical variations of the hepatic artery are important in the planning and performance of abdominal surgical procedures. Normal hepatic anatomy occurs in approximately $80 \%$ of cases, for the remaining 20\% multiple variations have been described. The purpose of this study was to review the existing literature on the hepatic anatomy and to stress out its importance in surgical practice. Two main databases were searched for eligible articles during the period 2000 - 2015, and results concerning more than 19,000 patients were included in the study. The most common variation was the replaced right hepatic artery (type III according to Michels classification) which is the chief source of blood supply to the bile duct.
\end{abstract}

Keywords: Celiac trunk; Hepatic artery; Review; Anatomic variation; Surgical practice

\section{Introduction}

For decades, arterial variations of the abdominal aorta have attracted the attention of anatomists and radiologists due to their prominent significance in surgical specialties. The first description of normal and aberrant celiac trunk anatomy was published in 1756 by Haller [1]. Lipshutz [2] seems to have been the first who suggested a classification of the celiac trunk into four types. Later, Adachi [3] presented a more detailed classification, while the two most commonly used classifications were suggested by Morita [4] and Michels [5]. Variations in the vascular pattern of the celiac trunk and its branches should be taken into consideration when planning surgical in-

\footnotetext{
Manuscript accepted for publication January 23, 2017

aDepartment of Anatomy of Medical School, Aristotle University of Thessaloniki, Thessaloniki, Greece

bDepartment of Surgery, Agios Dimitrios General Hospital, Thessaloniki, Greece

${ }^{\mathrm{c} C o r r e s p o n d i n g ~ A u t h o r: ~ A n a s t a s i o s ~ K a t s o u r a k i s, ~ D e p a r t m e n t ~ o f ~ S u r g e r y, ~ A g i-~}$ os Dimitrios General Hospital, Thessaloniki, Greece.

Email: tasoskatsourakis@hotmail.com
}

doi: https://doi.org/10.14740/jocmr2902w terventions on the abdominal part of the esophagus, stomach, duodenum, liver, pancreas, gallbladder and spleen [6]. Our study presents a review of the frequency of normal and aberrant hepatic arteries found in abdominal computed tomography angiographies, during operation and in cadavers.

\section{Methods}

A systematic search of the scientific literature was carried out using Pubmed and Scopus database for the years 2000 - 2015 in order to obtain access to all publications involving the anatomic variations of the hepatic artery.

The following terms and combinations of them were used: "hepatic", "artery", "anatomic", and "variations". The references of all the articles which were considered relevant were checked to find any studies missed. The criteria for inclusion of data in the study were the following: 1) The study was an original article or a review. 2) Only studies concerning adult humans were selected. 3) Populations overlapping with others were excluded. 4) Only articles written in English were used.

The classification of the celiac trunk was defined according to Michels. For each study considered eligible, the year of publication, the type of study (case report, case series, and systematic review) and the kind of patients (living or cadavers) were investigated.

\section{Results}

Twenty articles were retrieved using the described search strategy. All articles were analyzed in the review (Fig. 1).

A total of 19,013 patients were analyzed in our study (Table 1) [6-26]. In our review, $81 \%$ of cases displayed normal anatomy. A replaced right hepatic artery (RHA) arose from the superior mesenteric artery (SMA) in $3.7 \%$ of cases, while a replaced left hepatic artery (LHA) stemmed from the left gastric artery in 3\% of cases. Both a replaced RHA and a left one were found in $0.8 \%$ of cases, while an accessory LHA and an accessory RHA were present in $3.2 \%$ and $1.6 \%$ of cases, respectively. A common hepatic artery (CHA) originating from the SMA appeared in $1.2 \%$ of cases.

Finally, 784 cases $(4.1 \%)$ encountered in our study were rare unreported anomalies or more commonly unclassified 


\section{Articles using the terms "hepatic", "artery", "anatomic" and "variation" (Pubmed and Scopus) $\mathbf{n}=\mathbf{2 8 7}$}

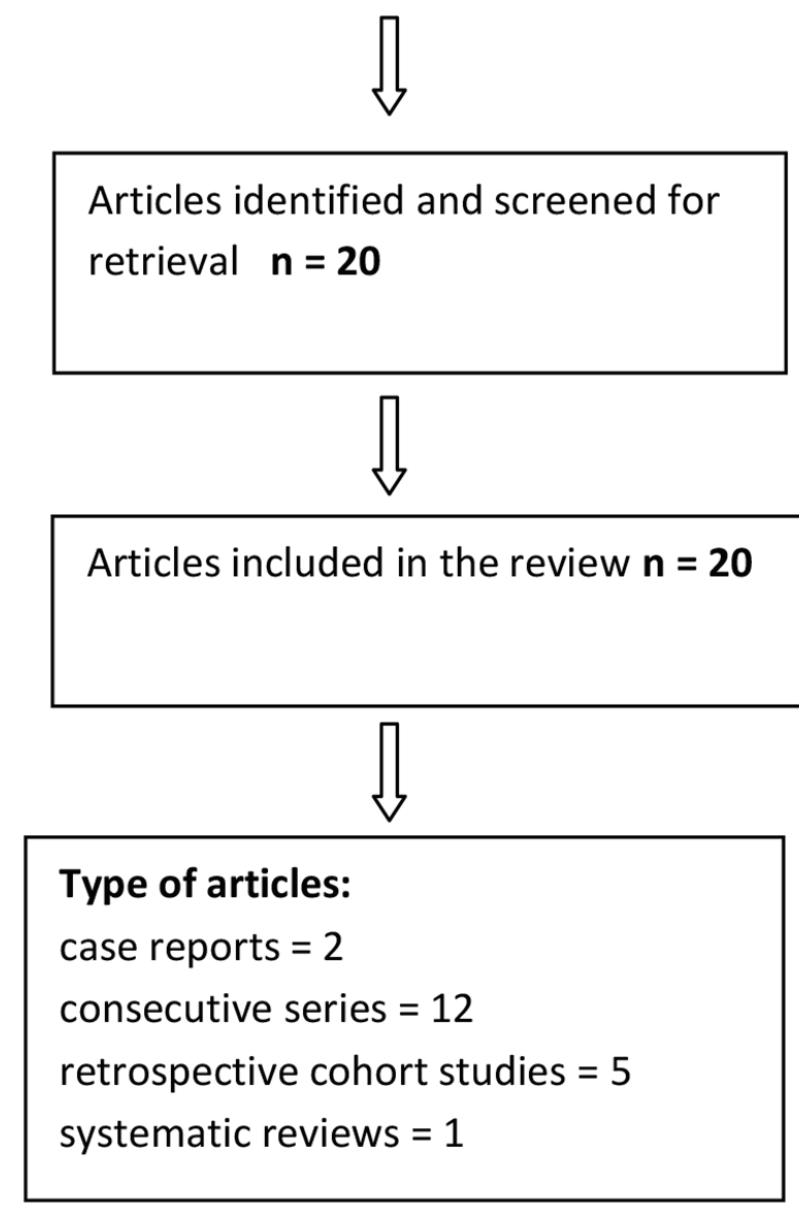

Figure 1. Summary of the literature search.

anomalies (Table 2).

\section{Discussion}

According to the available literature, trifurcation of tripus Halleri is reported with variable frequency, ranging from $60.0 \%$ to $94.2 \%$, and a more recent review by $\mathrm{Yi}$ et al reported that the trifurcation occurs in $87.6 \%(1,875 / 2,141)$ of subjects [16].

Studies regarding the hepatic artery variations are abundant in the literature. Hepatic arterial tree anomalies include replaced RHA in 11-21\% of cases and replaced LHA in 3.8$10 \%$ of cases, while accessory RHA and LHA have a frequency of $0.8-8 \%$ according to a recent review [27].

Embryologically, the celiac trunk derives from six pairs of ventral splanchnic vessels (subphrenic, upper, middle, lower ventricular and upper and lower intestinal). During the fetal development, these pairs span and disappear. However, the persistence of longitudinal channels between primitive vessels may lead to vascular anomalies or variations [28].

Knowledge of the anatomical variants in hepatic vascular structures is of great importance in general surgery, especially in hepatic and pancreatic surgery. This knowledge is also of great importance with regard to laparoscopic surgery, radiological procedures, and the treatment of penetrating injuries involving the peri-hepatic area. Computerized tomographic angiography (CTA) helps to clearly delineate the vascular anatomy preoperatively, which would help the surgeon by anticipation of a vascular anomaly. Every attempt should be made to carefully dissect and preserve anomalous vessels unless their division or resection is dictated by the need to obtain oncological clearance [29].

An international classification describing the principal variations in the vascular anatomy of the liver was proposed 
Table 1. Classification of the Articles According to the Number and Type of Patients

\begin{tabular}{lll}
\hline Author & No. of patients & Type of patients \\
\hline Paraskevas and Raikos [8] & 1 & Cadaver \\
\hline Prakash et al [6] & 50 & Cadaver \\
Chitra [9] & 50 & Cadaver \\
\hline Venieratos et al [7] & 77 & Cadaver \\
\hline Le Bian et al [10] & 2 & Living patient \\
Panagouli et al [11] & 12,196 & Living patient/cadaver \\
Schwartz et al [12] & 1 & Living patient \\
\hline Sureka et al [13] & 600 & Living patient \\
Chaib et al [14] & 60 & Cadaver \\
\hline Ramanadham et al [15] & 2 & Living patient \\
Yi et al [16] & 1 & Living patient \\
\hline Loschner et al [17] & 1,297 & Living patient \\
Lopez-Andujar et al [18] & 1,081 & Cadaver \\
\hline Koops et al [19] & 604 & Living patient \\
De Cecco et al [20] & 250 & Living patient \\
Coskun et al [21] & 48 & Living patient \\
Stemmler et al [22] & 63 & Living patient \\
Winston et al [23] & 371 & Living patient \\
Covey et al [24] & 600 & Living patient \\
\hline Saba and Mallarini [25] & 1,629 & Living patient \\
Sebben et al [26] & 30 & Cadaver \\
\hline & & \\
\hline
\end{tabular}

by several authors, including Adachi in 1928, Michels in 1966, Hiatt in 1994 and Abdullah in 2006. Despite these studies, there are still some rare hepatic variations which are not found in these classifications [30].

Michels described the hepatic arterial anatomy and its variations using the results of 200 cadaveric dissections and identified 10 types of hepatic arterial anatomy: type I: normal pattern; type II: a replaced LHA from the left gastric artery; type

Table 2. Distribution of the Found Variants

\begin{tabular}{lll}
\hline Michels type & $\mathbf{N = 1 9 , 0 1 3}$ & $\mathbf{1 0 0 \%}$ \\
\hline I & 15,342 & 81 \\
II & 556 & 3 \\
III & 710 & 3.7 \\
IV & 163 & 0.8 \\
V & 592 & 3.2 \\
VI & 309 & 1.6 \\
VII & 38 & 0.2 \\
VIII & 66 & 0.35 \\
IX & 245 & 1.2 \\
X & 5 & 0.04 \\
Not yet classified types & 784 & 4.1 \\
\hline
\end{tabular}

III: a replaced RHA from the SMA; type IV: replaced RHA and LHA; type V: an accessory LHA; type VI: an accessory RHA; type VII: accessory RHA and LHA; type VIII: a replaced RHA or LHA with other hepatic artery being an accessory one; type IX: the hepatic trunk as a branch of the SMA; and type X: the CHA from the left gastric artery [31].

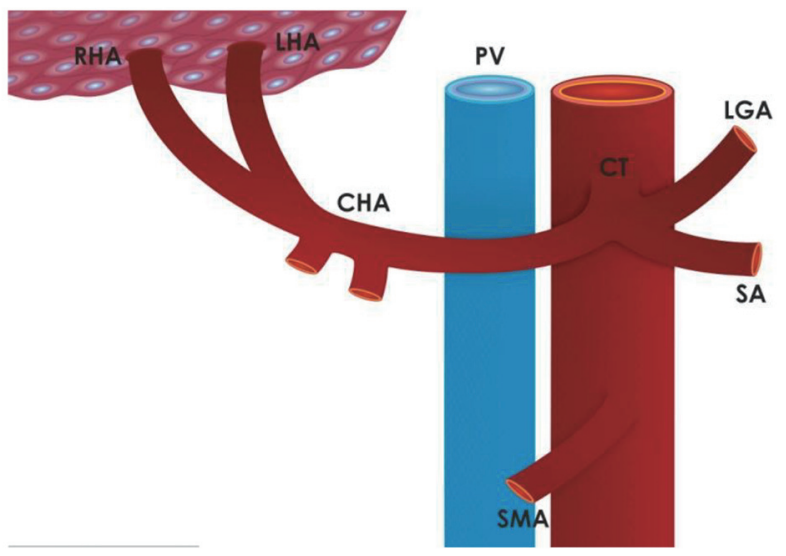

Figure 2. Type I normal anatomy according to Michels classification (81\% of cases). RHA: right hepatic artery; LHA: left hepatic artery; CHA: common hepatic artery; CT: celiac trunk; PV: portal vein; LGA: left gastric artery; SA: splenic artery; SMA: superior mesenteric artery. 


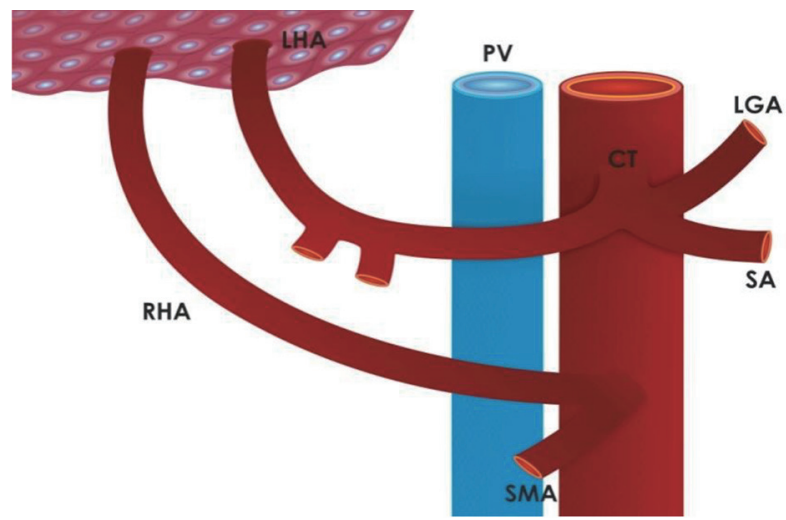

Figure 3. Type III a replaced right hepatic artery according to Michels (3.7\% of cases). RHA: right hepatic artery; LHA: left hepatic artery; CHA: common hepatic artery; CT: celiac trunk; PV: portal vein; LGA: left gastric artery; SA: splenic artery; SMA: superior mesenteric artery.

The classification of Michels was modified by Hiatt who distinguishes six categories: the normal anatomy - Hiatt type I, the LHA arising from the left gastric artery - Hiatt type II, the RHA arising from the SMA - Hiatt type III, every combination of a double replaced pattern - Hiatt type IV, the CHA originating as a branch of the SMA - Hiatt type V; and the abnormality consisting of an isolated aortic origin of the CHA, which Hiatt introduced as type VI instead of including the rare variant with a CHA arising from the left gastric artery $[8,32]$.

Our study comprises a review of Pubmed and Scopus databases. It looks into the anatomical variations of the hepatic artery as they are recorded in 20 articles. A total number of 19,013 cases of adult humans were included. We have used the Michels classification because from the surgical point of view we believe that is more complete since it establishes the differences between "an accessory" and "a replaced" artery concepts not explained in more recent classifications. Type III (replaced RHA) is the most common variant (3.7\%) according to Michels (Figs. 2-4). These vessels usually pass lateral and

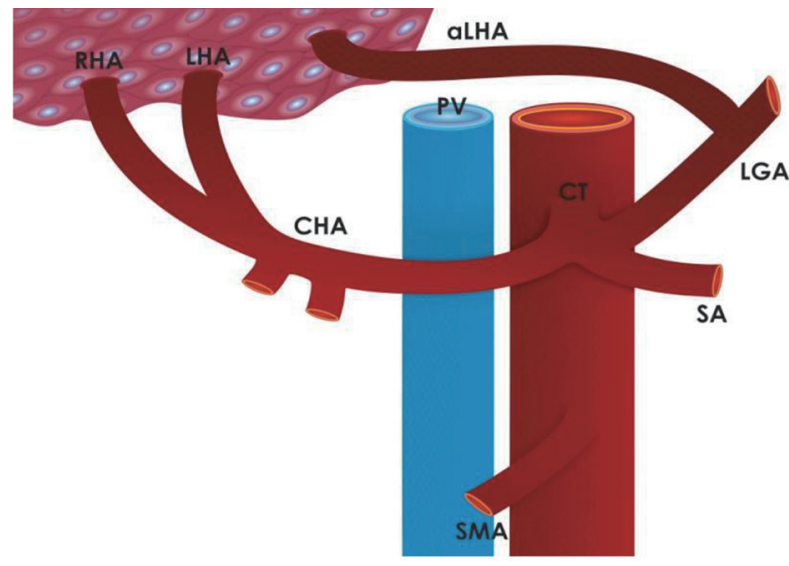

Figure 4. Type $\mathrm{V}$ an accessory left hepatic artery according to Michels (3.2\% of cases). RHA: right hepatic artery; LHA: left hepatic artery; CHA: common hepatic artery; CT: celiac trunk; PV: portal vein; LGA: left gastric artery; SA: splenic artery; SMA: superior mesenteric artery; aLHA: accessory left hepatic artery.

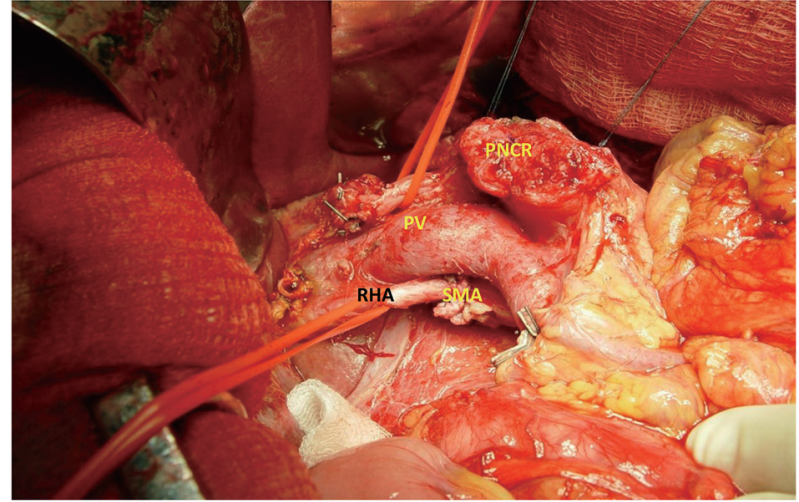

Figure 5. Replaced RHA originating from the SMA. PNCR: pancreas; PV: portal vein; RHA: right hepatic artery; SMA: superior mesenteric artery (from the Archives 2014 Surgical Department Agios Dimitrios, Thessaloniki).

behind the portal vein and enter the hepatoduodenal ligament posterolateral to the bile duct and can be felt in this location when palpating the structures at the porta with the finger in the foramen of Winslow. However, there have been reports of such vessels traveling behind or through the head of the pancreas, in which case they are susceptible to damage. The danger in case of injury to a replaced RHA is its effect on the liver and specifically the bile duct vascularity with the attendant risk of a leak in the bilioenteric anastomosis, as Traverso et al outline (Fig. 5). This is because the RHA is the chief source of blood supply to the bile duct. Type V (accessory LHA) is the second most common anomaly (3.2\%). In this variation, the artery courses along the path of the replaced vessel and, on dissecting, the vessel is found to be accessory in the presence of the native LHA running along its normal course. Injury to these vessels is not associated with any major problems [27]. However, the replaced CHA arises from the SMA by a common trunk referred to as the hepatomesenteric trunk and has been classified as type 9 by Michels. The incidence of such an anomaly has been reported in literature to range from $0.4 \%$ to $4.5 \%$, while in our review was $1.2 \%$. Accidental ligation of this vessel can lead to ischemia of the bilioenteric anastomosis and a consequent leak.

We have to point out that the not classified types are the more frequent anomalies. The above results are similar to Michels's classification as well as consistent with most of the published articles.

In conclusion, the hepatic arterial anatomy represents one of many "lessons for the general surgeon". These arterial patterns are of importance in the planning and performance of all surgical and radiological procedures in the upper abdomen.

\section{References}

1. Haller A. Icones anatomicae in quibus aliquae partes corporis humani delineatae proponuntur et arteriarum potissimum historia continetur. Gottingen. 1756: Vandenhoeck.

2. Lipshutz B. A Composite Study of the Coeliac Axis Artery. Ann Surg. 1917;65(2):159-169. 
3. Adachi B. Das Arteriensystem der Japaner. Vol.2. verlag der Kaiserlich- Japanischen Universitat zuKyoto. 1928.

4. Morita M. Reports and conception of three anomalous cases on the area of the celiac and the superior mesenteric arteries. Igaku Kenkyu (Acta Med). 1935;9:159-172.

5. Michels NA. Blood supply and anatomy of the upper abdominal organs, with a descriptive atlas. Lippincott, Philadelphia. 1955;139-143.

6. Prakash, Rajini T, Mokhasi V, Geethanjali BS, Sivacharan PV, Shashirekha M. Coeliac trunk and its branches: anatomical variations and clinical implications. Singapore Med J. 2012;53(5):329-331.

7. Venieratos D, Panagouli E, Lolis E, Tsaraklis A, Skandalakis P. A morphometric study of the celiac trunk and review of the literature. Clin Anat. 2013;26(6):741-750.

8. Paraskevas GK, Raikos A. Multiple aberrant coeliac trunk ramifications. Singapore Med J. 2011;52(7):e147-149.

9. Chitra R. Clinically relevant variations of the coeliac trunk. Singapore Med J. 2010;51(3):216-219.

10. Zarzavadjian Le Bian A, Costi R, Blangy S, Sbai-Idrissi MS, Smadja C. Pancreaticoduodenectomy in the presence of a common hepatic artery originating from the superior mesenteric artery. Technical implications. Int J Surg. 2015;17:1-4.

11. Panagouli E, Venieratos D, Lolis E, Skandalakis P. Variations in the anatomy of the celiac trunk: A systematic review and clinical implications. Ann Anat. 2013;195(6):501-511.

12. Schwarz L, Huet E, Yzet T, Fuks D, Regimbeau JM, Scotte M. An extremely uncommon variant of left hepatic artery arising from the superior mesenteric artery. Surg Radiol Anat. 2014;36(1):91-94.

13. Sureka B, Mittal MK, Mittal A, Sinha M, Bhambri NK, Thukral BB. Variations of celiac axis, common hepatic artery and its branches in 600 patients. Indian J Radiol Imaging. 2013;23(3):223-233.

14. Chaib E, Bertevello P, Saad WA, Pinotti HW, Gama-Rodrigues $J$. The main hepatic anatomic variations for the purpose of split-liver transplantation. Hepatogastroenterology. 2007;54(75):688-692.

15. Ramanadham S, Toomay SM, Yopp AC, Balch GC, Sharma R, Schwarz RE, Mansour JC. Rare hepatic arterial anatomic variants in patients requiring pancreatoduodenectomy and review of the literature. Case Rep Surg. 2012;2012:953195.

16. Yi SQ, Terayama H, Naito M, Hirai S, Alimujang S, Yi N, Tanaka S, et al. Absence of the celiac trunk: case report and review of the literature. Clin Anat. 2008;21(4):283286.

17. Loschner C, Nagel SN, Kausche S, Teichgraber U. Hepatic arterial supply in 1297 CT-angiographies. Rofo. 2015;187(4):276-282.

18. Lopez-Andujar R, Moya A, Montalva E, Berenguer M, De Juan M, San Juan F, Pareja E, et al. Lessons learned from anatomic variants of the hepatic artery in 1,081 transplanted livers. Liver Transpl. 2007;13(10):1401-
1404.

19. Koops A, Wojciechowski B, Broering DC, Adam G, Krupski-Berdien G. Anatomic variations of the hepatic arteries in 604 selective celiac and superior mesenteric angiographies. Surg Radiol Anat. 2004;26(3):239-244.

20. De Cecco CN, Ferrari R, Rengo M, Paolantonio P, Vecchietti F, Laghi A. Anatomic variations of the hepatic arteries in 250 patients studied with 64-row CT angiography. Eur Radiol. 2009;19(11):2765-2770.

21. Coskun M, Kayahan EM, Ozbek O, Cakir B, Dalgic A, Haberal M. Imaging of hepatic arterial anatomy for depicting vascular variations in living related liver transplant donor candidates with multidetector computed tomography: comparison with conventional angiography. Transplant Proc. 2005;37(2):1070-1073.

22. Stemmler BJ, Paulson EK, Thornton FJ, Winters SR, Nelson RC, Clary BM. Dual-phase 3D MDCT angiography for evaluation of the liver before hepatic resection. AJR Am J Roentgenol. 2004;183(6):1551-1557.

23. Winston CB, Lee NA, Jarnagin WR, Teitcher J, DeMatteo RP, Fong Y, Blumgart LH. CT angiography for delineation of celiac and superior mesenteric artery variants in patients undergoing hepatobiliary and pancreatic surgery. AJR Am J Roentgenol. 2007;189(1):W13-19.

24. Covey AM, Brody LA, Maluccio MA, Getrajdman GI, Brown KT. Variant hepatic arterial anatomy revisited: digital subtraction angiography performed in 600 patients. Radiology. 2002;224(2):542-547.

25. Saba L, Mallarini G. Anatomic variations of arterial liver vascularization: an analysis by using MDCTA. Surg Radiol Anat. 2011;33(7):559-568.

26. Sebben GA, Rocha SL, Sebben MA, Parussolo Filho PR, Goncalves BH. Variations of hepatic artery: anatomical study on cadavers. Rev Col Bras Cir. 2013;40(3):221226.

27. Shukla PJ, Barreto SG, Kulkarni A, Nagarajan G, Fingerhut A. Vascular anomalies encountered during pancreatoduodenectomy: do they influence outcomes? Ann Surg Oncol. 2010;17(1):186-193.

28. Kosaka M, Horiuchi K, Nishida K, Taguchi T, Murakami T, Ohtsuka A. Hepatopancreatic arterial ring: bilateral symmetric typology in human celiaco-mesenteric arterial system. Acta Med Okayama. 2002;56(5):245-253.

29. Suzuki T, Nakayasu A, Kawabe K, Takeda H, Honjo I. Surgical significance of anatomic variations of the hepatic artery. Am J Surg. 1971;122(4):505-512.

30. Gurgacz AM, Horbaczewska A, Klimek-Piotrowska W, Walocha J. Variations in hepatic vascularisation: lack of a proper hepatic artery. Two case reports. Folia Morphol (Warsz). 2011;70(2):130-134.

31. Michels NA. Newer anatomy of the liver and its variant blood supply and collateral circulation. Am J Surg. 1966;112(3):337-347.

32. Hiatt JR, Gabbay J, Busuttil RW. Surgical anatomy of the hepatic arteries in 1000 cases. Ann Surg. 1994;220(1):5052. 